\title{
AIR POLLUTION MONITORING SYSTEM BASED ON ESP8266 USING ARDUINO
}

\author{
Anuradha S Dige \\ M. Tech. Student \\ Department of CSE \\ M. S. Bidve Engineering College, Latur, \\ Maharashtra, India
}

\begin{abstract}
Internet of Things (IoT) could likewise be an overall arrangement of "Brilliant Gadgets" which can detect and interface with their environmental factors and collaborate with users and different frameworks. Worldwide contamination is perhaps the most worrying of our period. Existing observing frameworks have second rate exactness, low affectability, and wish research facility examination. Accordingly, improved observing frameworks are required. To beat the issues of existing frameworks, we propose a contamination observing framework. An IoT unit was readied utilizing a few sensors, Arduino IDE and a Wi-Fi module. This unit is typically genuinely positioned in different urban communities to checking contamination. The sensors assemble information from environment and forward the data to the Arduino IDE. The Arduino IDE communicates the information to the cloud through the Wi-Fi module. The proposed framework is anticipating the norm of air utilizing various sensors and put away information in the database and cloud, so anyone can get or recover information from anyplace whenever they want. The web interface is also to access and retrieve data time to time and sorted data to understand easily to the user.
\end{abstract}

Keywords-IOT, Arduino, ERG, TVA, CO2, STIM.

\section{INTRODUCTION}

The beginning line of air quality observing is to initially consider if an area has a contamination issue. Observing aides in evaluating the degree of contamination regarding the encompassing air quality guidelines. Guidelines are an administrative measure to line the objective for contamination decrease and accomplish clean air. Powerful observing assists with securing against extraordinary occasions by cautioning individuals and start activity. We direct a sum of 12 contaminations, including SO2, NO2, PM10, PM2.5 (particulate matter of up to 10 microns, and up to 2.5 micron size), ozone, lead, arsenic, nickel, CO, NH3, benzene. Across urban areas, just SO2, NO2, and RSPM/PM10 are observed consistently. Different poisons, as PM2.5, O3, CO, BTX, hefty metals are observed in chosen urban communities as limit remains being fabricated. India has set an objective for states to fulfill Public Surrounding Air Quality Guidelines (NAAQS) in metropolitan regions.

\author{
Shrikant R Tandle \\ Assistant Professor \\ Department of CSE \\ M. S. Bidve Engineering College, Latur, \\ Maharashtra, India
}

The current public air quality observing organization is confined in scope in light of the fact that the recorded qualities are characteristic and there tremendous time slacking report the data. So constant activity is absurd. Additionally, the contribution of changed observing offices, work force, and hardware in examining, compound examinations, and information detailing brings vulnerability and predispositions. However, even with the common framework the rebelliousness with guidelines in urban communities is discovered to be gigantic. Upwards of 131 urban communities are surpassing as far as possible for PM 10 and 18 urban communities are surpassing as far as possible for NO2. In this way, it's the activity that issues while we overhaul our checking frameworks.

\section{LITERATURE SURVEY}

As indicated by a report distributed recently by the planet Wellbeing Association, contamination presently slaughters around 7,000,000 individuals yearly, around the world. This records for the greatest sum together in eight passing and is by a long shot the main greatest natural wellbeing hazard.

Among different poisons, air screens survey the measures of $(\mathrm{CO} 2)$, carbon monoxide gas $(\mathrm{CO})$, nitrogen oxides (NOx), ozone (O3) and particulate 2.5 (PM2.5). This permits us to find out where and why contamination happens, all together that we won't just effectively maintain a strategic distance from excessively tainted territories in our day by day schedules yet in addition endeavor to execute measures to check such contamination.

In 2010, the town of Fortress Worth, Texas dispatched Eastern Exploration Gathering, Inc. (ERG) to play out an air quality checking study zeroed in on gas advancement inside as far as possible. ERG (2011) gathered information from 375 zones, eight blower stations, a gas preparing plant, a saltwater treatment office, a penetrating activity, a pressure driven cracking activity, and a finish activity. Brief outflows were checked utilizing an optical gas imaging (OGI) camera, a harmful fume analyzer, a Hey Stream Sampler and chrome steel canisters. ERG followed EPA Strategy 21 techniques to study $10 \%$ of valves, connectors and accordingly different segments utilizing the TVA, furthermore to any gear that huge holes were demonstrated by the OGI camera. The volumetric progression of holes at or over $500 \mathrm{ppm}$ by volume was estimated utilizing the Hello Stream Sampler. Chosen gas tests were gathered in chrome steel canisters for 


\section{International Journal of Engineering Applied Sciences and Technology, 2020 \\ Vol. 5, Issue 6, ISSN No. 2455-2143, Pages 228-235 \\ Published Online October 2020 in IJEAST (http://www.ijeast.com)}

disconnected research facility investigation utilizing a gas chromatograph-mass spectrometer (GC-MS).

ERG assessed emanations of all out natural mixes (TOC) from the overviewed destinations of 20,818 tons for every annum, very $75 \%$ of which came from well cushions. Around $98 \%$ of these emanations were for poisons with moderately low poison levels, albeit a few toxins with high poison levels (e.g., benzene) were additionally radiated. At a little subset of destinations, there indicated huge emanation occasions moreover connected with failing gear, for example, open incubates or eroded rooftops on capacity tanks.

\subsection{Air Monitoring in the Home}

It very well may be speaking to see air contamination as a difficult outside and all things considered, one that can be tried not to by blockade yourself in your home. Notwithstanding, numerous homes really contain fundamentally more elevated levels of contamination than nature, for the basic explanation that helpless ventilation implies there is no place for toxins to scatter.

Indoor air screens, for example, Speck are explicitly intended to screen levels of hurtful contaminations discovered inside and offer proposals of how to lessen their focus and accomplish an ideal indoor climate.

\subsection{Industrial Air Monitoring}

Its presence of mind that the individuals who work in a processing plant or plant will be unmistakably more in danger of breath of destructive synthetic compounds and gases because of their drawn-out presentation to discharges. Accordingly, satisfying wellbeing guidelines in a modern setting is of central concern, both for boss and representative. The article Personal Monitoring versus Industrial Hygiene Choices in Gas Monitoring Instrumentation takes a gander at two different strategies for surveying mechanical contamination and looks at their preferences and drawbacks in the field.

\subsection{Open Source Air Monitoring}

While legislative information gathered from in excess of 1,000 air checking locales around the UK can offer a fundamental outline of the province of British air, it does little to help those in explicit conditions. For instance, the information will be profoundly incorrect on the off chance that you live close to a bustling convergence or by a carbonrambling force plant.

Thus, numerous impetuses have been embraced to manage the cost of us a more thorough and receptive perspective on the air in explicit regions. Wearable tech, for example, sensors coordinated into Smartphones or screens that can be cut onto packs or dress, are getting increasingly well known. By means of this strategy, the man on the road can be changed into an instrument estimating air quality any place he goes, giving exact, constant data about air quality in an assortment of settings.
Besides, it's not absurd to believe that soon, basically everybody will convey these screens, subsequently driving air quality observing into another period and permitting us a superior image of the neatness of the air we inhale than any time in recent memory.

[1] Air quality checking frameworks that can screen gas, for example, $\mathrm{CO}$ and Sox on surrounding air in a constant and can be gotten to with web line have been created. Sensor component on this framework depends on Nano organized zinc oxide slender film blended utilizing wet substance course. Observing framework is planned utilizing Arduino Uno microcontroller as simple to advanced converter, and ethernet shield for information transmission, PC worker for information base focus and information procurement. The information from this observing framework can be gotten to and seen as site page. The sensor component that utilized in this framework is made at nanostructure so it will yield high affectability. The ideal test boundaries that will be utilized are temperature, introduction time to gas target, examining period, and furthermore proportion for recovery time. Estimations will be held under very much controlled and falsely $\mathrm{CO} / \mathrm{Sox}$ contaminated air.

[2] Due to the expanding industrialization and the enormous urbanization, air contamination checking is being considered as one of the significant difficulties of brilliant urban areas. Many air contaminations observing frameworks have been proposed in the writing, among which remote sensor networks appear to be a main arrangement. A cautious organization of sensors is in this way important to improve Performances while guaranteeing an insignificant budgetary expense. In this paper, the citywide remote sensor networks are thought of and tackle the base cost hub situating issue for air contamination checking. The proposed framework has an effective methodology that expects to discover ideal sensors and sinks areas while guaranteeing air contamination inclusion and organization availability. In contrast to the majority of the current strategies, which depend on basic and conventional location models, our methodology depends on the spatial investigation of contamination information, permitting to consider the idea of the contamination wonder. [3] A Wi-Fi based fitting and sense brilliant gadget for devoted air contamination observing utilizing Internet of Things is planned. This framework planned on gadget to cloud design in IoT for checking air contamination definitely. When the sensor hub peruses singular contaminations piece and area facilitates, Air quality record (AQI) will be determined utilizing direct divided rule with more noteworthy incentive in AQI table and Max administrator accumulation strategy. In light of AQI esteem, comparing LED will be impelled for sign and wellbeing sway with insurance steps messages will be shown on the screen. Each one of that information will be pushed to thing talk distributed storage, an open source application Programming interface for IoT based gadgets. These pushed information alongside Date and time can be recovered as a different dominate sheet for future investigation. Through thing view android application, ongoing contamination level with area can be imagined regarding line diagram. With the usage of this 


\section{International Journal of Engineering Applied Sciences and Technology, 2020 \\ Vol. 5, Issue 6, ISSN No. 2455-2143, Pages 228-235 \\ Published Online October 2020 in IJEAST (http://www.ijeast.com)}

minimal effort and little size keen gadget, alarm can be given to individuals to wear hostile to contamination cover and reroute way in transportation where there is high air contamination guaranteeing high dependability and consistency.

Remote Sensor Network (WSN) is a functioning field of examination because of its arising significance in numerous applications including climate and living space checking, medical services applications, traffic light and military organization frameworks. With the ongoing advancement of Micro-Electro-Mechanical Systems (MEMS) innovation whereby sensors are decreasing and more adaptable, WSN guarantees numerous new application territories sooner rather than later. Run of the mill uses of WSNs incorporate observing, following and controlling. A portion of the particular applications are territory observing, object following, atomic reactor controlling, fire recognition, traffic checking, and so on Starting improvement into WSN was basically persuaded by military applications. Nonetheless, WSNs are currently utilized in numerous regular citizen application territories for business and mechanical use, including climate and natural surroundings observing, medical services applications, home computerization, atomic reactor controlling, fire identification and traffic signal. This change from the utilization of WSN exclusively in military applications has been roused because of the idea of WSNs which can be sent in wild zones, where they would stay for a long time, to screen some natural factors, without the need to energize/supplant their capacity supplies. Such attributes help to beat the troubles and significant expenses engaged with checking information utilizing wired sensors. The following are a few territories where WSN have been effectively conveyed to screen the climate.

The air and sound contamination checking framework is totally significant for identifying wide scope of gases, additionally sensors have long lifetime, effectively accessible, less cost, simple to deal with and are reduced. Nature of air can be checked indoor just as open air. This framework has straightforward drive circuit, takes a shot at ongoing and has visual yield. The principle goal of this paper is to guarantee that the air and sound contamination is checked and kept in charge by taking measure as needs be. The proposed paper has certain constraints with respect to dampness which ought to be under 95 percent and careful estimation of defiling gases can't be identified in ppm. This paper can be utilized for checking contamination level and furthermore to forestall abundance of contamination which can cause immense issue in future. This paper gives a thought on how we can give moment caution to the specialists. The practical IOT innovation is utilized. Consequently, air and sound contamination are checked by utilizing this innovation. [4] The Automatic Air and Sound administration framework is a stage forward to contribute an answer for the greatest danger. The air and sound checking framework defeats the issue of the exceptionally contaminated zones which is a significant issue. It underpins the new innovation and adequately bolsters the sound life idea. This framework has highlights for individuals to screen the measure of contamination on their cell phones utilizing the application. In this way, it turns out to be truly solid and effective for the Municipal authorities alongside the Civilians to screen climate. Letting regular citizens additionally associated with this cycle increases the value of it. As regular folks are currently similarly mindful and inquisitive about their current circumstance, this idea of IOT is useful for the government assistance of the general public. Also, it is executed utilizing the most recent innovation. [5]

\section{EXISTING SYSTEM}

A portion of the current instruments for air contamination observing are Fourier change infrared (FTIR) instruments, gas chromatographs and mass spectrometers. These instruments give genuinely precise and particular gas readings. A gas sensor that is conservative, strong with adaptable applications and ease could be a similarly powerful other option. A portion of the gases checking advances are electrochemical, infrared, reactant globule, photograph ionization and strong state. The current observing framework to a great extent utilizes savvy transducer interface module (STIM) with semiconductor gas sensors which utilizes the 1451.2 norm. STIM was found to a proficient observing framework yet for the force prerequisites and capacity to extend for enormous arrangement. One of the huge scope sensor networks for checking and determining is Environment Observation and Forecasting System (EOFS). Air contamination observing framework dependent on geo sensor network with control activity and versatile examining rates proposed in additionally can't be huge organization because of significant expense.

\subsection{A Smart Air Pollution Monitoring System}

The library in the Arduino was stacked and a message was delivered off the LCD. Air quality data was accumulated using the MQ135 sensor. The adjusted sensor made the straightforward yield voltage relating to the centralization of sullying gases in Parts per Million (ppm). The data are first appeared on the LCD screen and subsequently delivered off the Wi-Fi module. The Wi-Fi module moves the purposeful data valve to the specialist through web. The Wi-Fi module is organized to move assessed data an application on a far off laborer called "Thing talk". The online application gives overall induction to assessed data by methods for any contraption that has web affiliation capacities. Data accumulated from the sensor was changed over into a string and used to revive the information transported off the distant laborer.

\subsection{Air Pollution Monitoring System}

The current segment presents the movement of power nimbly circuits amassed using channels, rectifiers, and a while later voltage regulators. Starting with an air-conditioner voltage, a predictable DC voltage is gotten by rectifying the air conditioner voltage, by then filtering to a DC level, finally figuring out how to sort an ideal out DC voltage. The rule is normally gained from an air-conditioner voltage regulator 


\section{International Journal of Engineering Applied Sciences and Technology, 2020 \\ Vol. 5, Issue 6, ISSN No. 2455-2143, Pages 228-235 \\ Published Online October 2020 in IJEAST (http://www.ijeast.com)}

unit, which proceed as in the past if the data DC voltage varies or the yield load related with DC voltage changes.

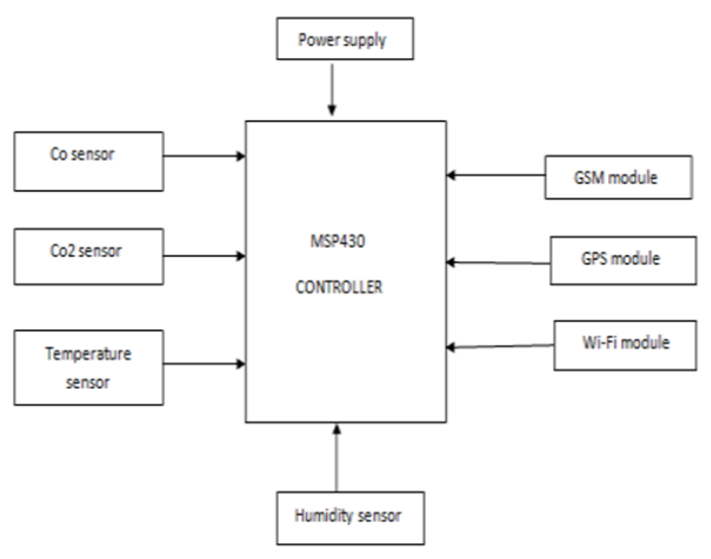

Figure 1 Hardware Description

A square graph containing the bits of an ordinary force effortlessly is shown as follows. The Air conditioner voltage routinely $120 \mathrm{Vrms}$ is related with transformer which steps that air conditioner voltage down to the level for the ideal DC yield. A diode rectifier that gives a full-wave changed voltage that is from the start filtered by a fundamental capacitor channel to make a DC voltage. A controlled circuit can use this DC commitments to give a DC voltage that has altogether less wave voltage just as remains as before DC regard whether or not the data DC voltage varies reasonably or the pile related with the yield DC voltage changes this voltage rule is commonly gotten using one of the different standard voltage rule IC unit.

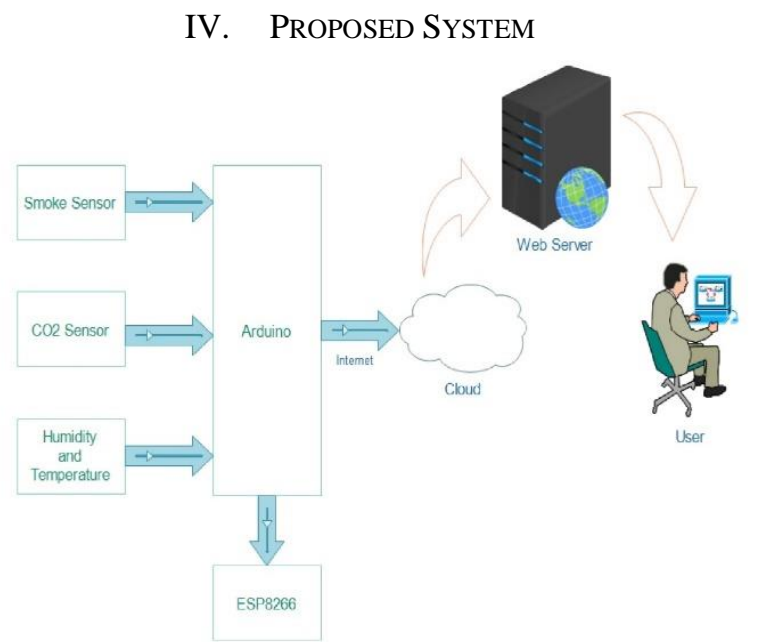

Figure 2 Proposed System

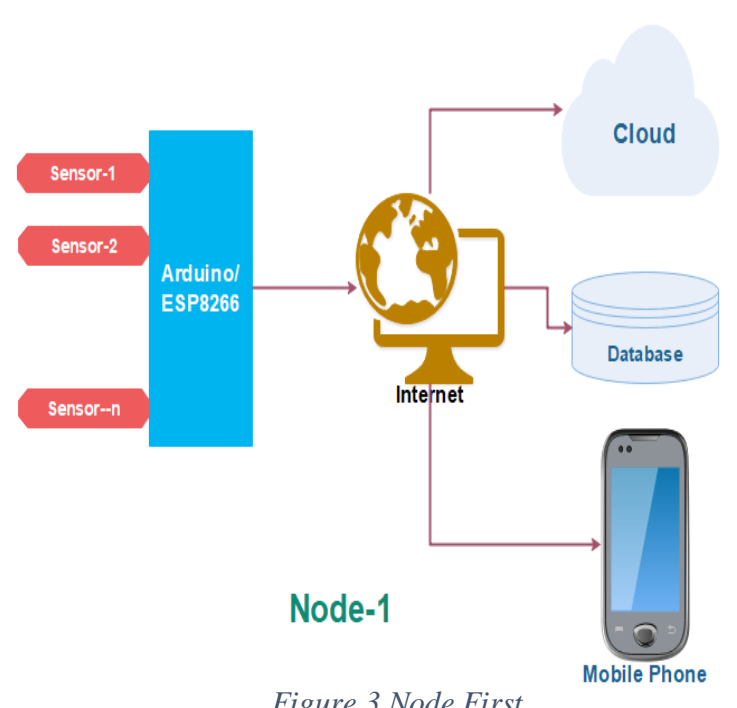

Figure 3 Node First

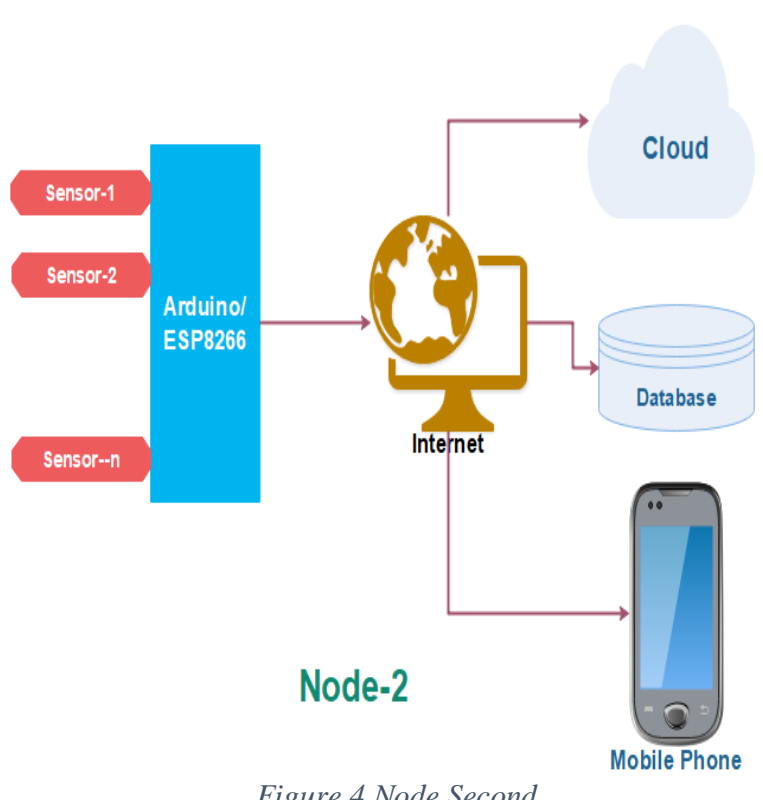

As of now we will make an IOT Based Air Contamination Observing Framework in which we will screen the Air Quality over a webserver utilizing web and will trigger rebuke when the air quality goes down past a specific level, proposes when there are agreeable extent of unsafe gases are available distinguishable all around like $\mathrm{CO} 2$, smoke, liquor, benzene, and NH3. It will show the air quality on the site page with the target that we can screen it no issue using any and all means.

In this proposed structure, two center points will be used. The Arduino microcontroller used to get to assessments of sensors and boat off laborer using Wi-Fi device. The laborer will store regards in database, so the customer will get a history of sensors regards. The characteristics can be taken care of and transport off the cloud to see current assessments of the sensor. The yield will be on the PC and android cell phone. The assessments of sensors can be gotten to use the page besides. The center points are orchestrated at different 


\section{International Journal of Engineering Applied Sciences and Technology, 2020 \\ Vol. 5, Issue 6, ISSN No. 2455-2143, Pages 228-235 \\ Published Online October 2020 in IJEAST (http://www.ijeast.com)}

territory and the tainting level can be distinguished and store on the database. From that database the characteristics can be brought at whatever point and wherever. The centers are two only so here we are not using GPS for territory, as opposed to it we will use the photos of the region.

\section{IMPLEMENTATION AND RESULT}

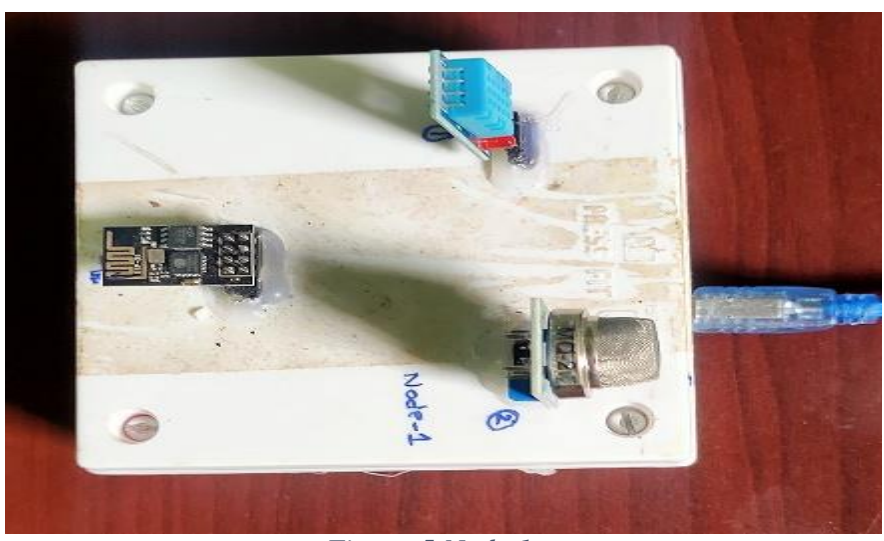

Figure 5 Node 1

The figure no. 3 shows the hardware connections with sensors of Node-1

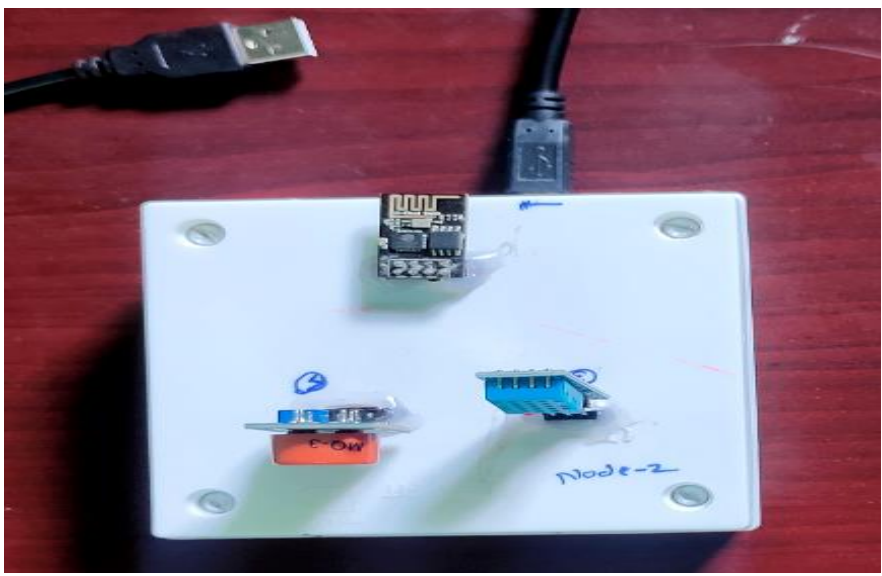

Figure 4 Node 2

The figure no. 4 shows the hardware connections with sensors of Node-2

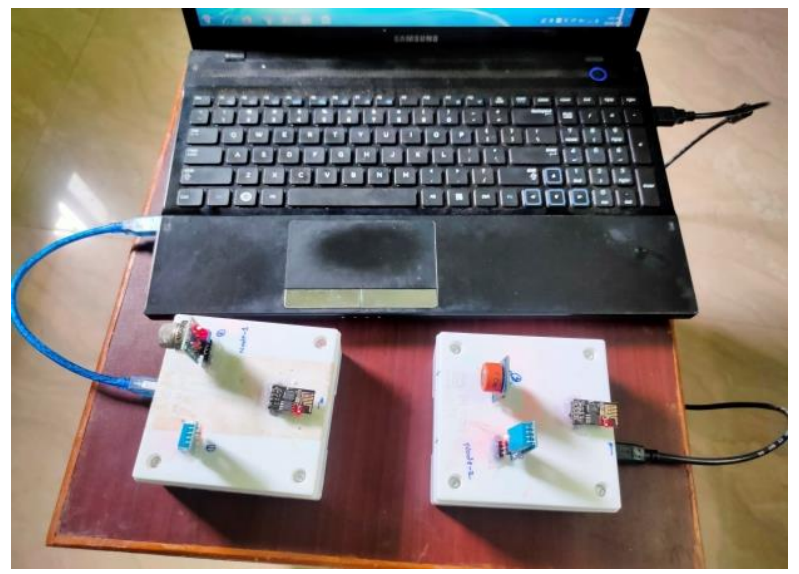

Figure 5 Connections
The figure no. 5 shows the hardware connections with sensors of Node-1 and Node- 2 with laptop connection.

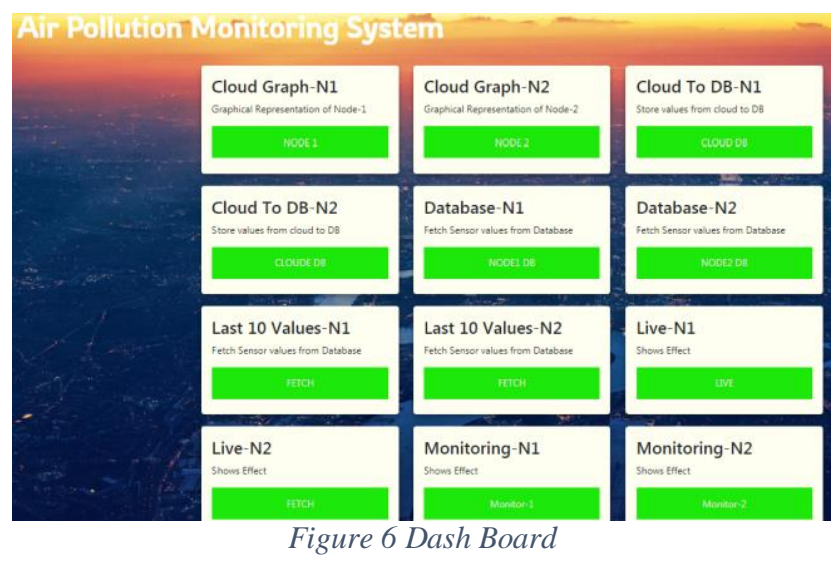

Above figure 6 shows, the front page of project, which contains Graph of Node first, second. The node first and second sensors values inserted in database from cloud. Node first and second all values shows from database. The last 10 values shows of Node first and second. Last block shows the live data of Node first and second.

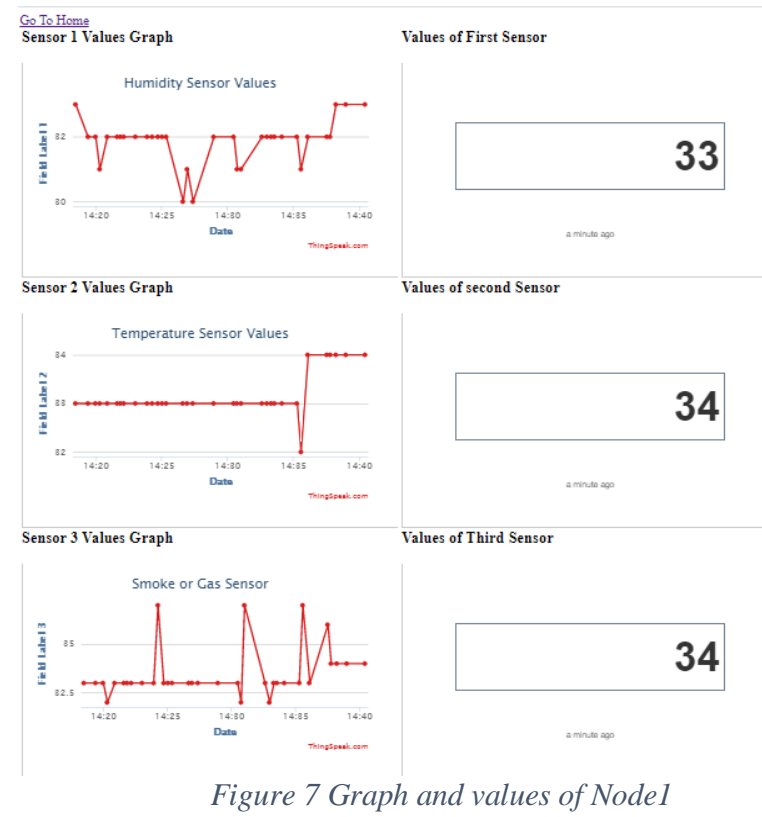

The above figure 7 shows the graph of node- 1 and respective sensors values. 
International Journal of Engineering Applied Sciences and Technology, 2020

Vol. 5, Issue 6, ISSN No. 2455-2143, Pages 228-235

Published Online October 2020 in IJEAST (http://www.ijeast.com)

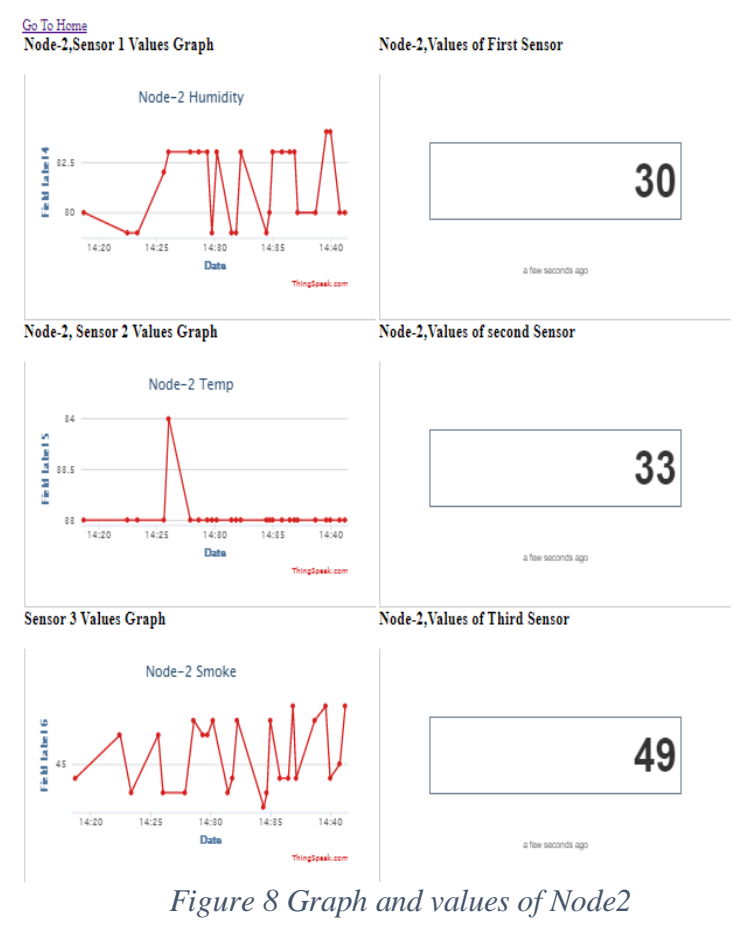

The above figure 8 shows the graph of node- 1 and respective sensors values.

Value is Retrieving Please wait

Figure 9

Retriving values from cloud to database.

Sensor Values Inserted successfully

Figure 10

Data inserted from cloud to database.

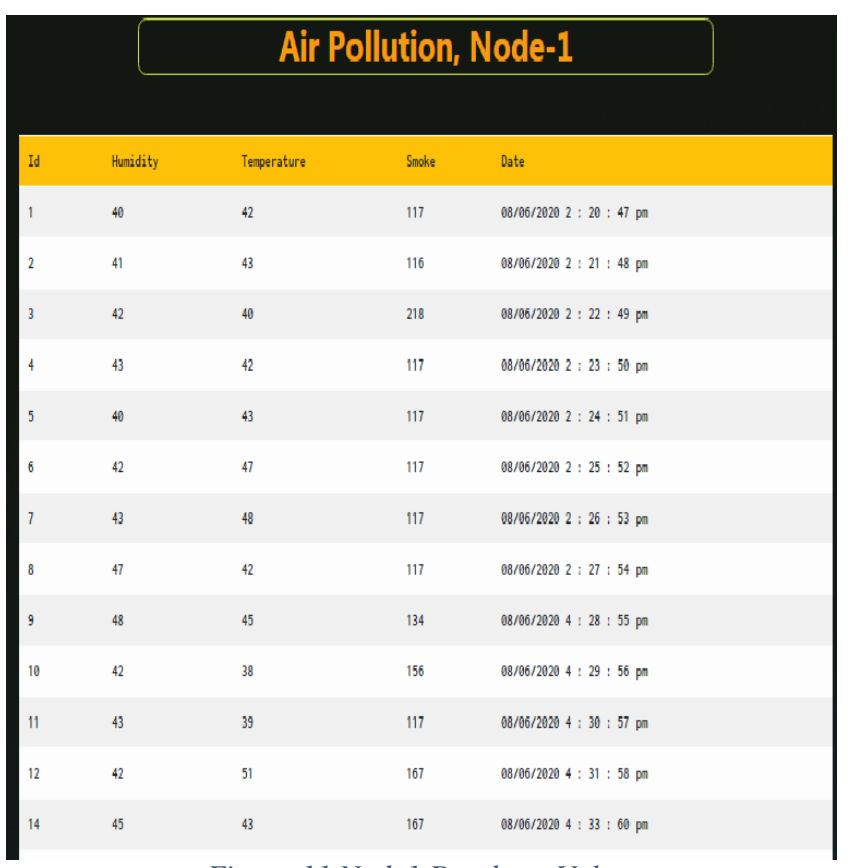

Figure 11 Node1 Database Values

Figure 11 shows the all database values from database. Air Pollution, Node-2

\begin{tabular}{|c|c|c|c|c|}
\hline Id & Humidity & Temperature & Smoke & Date \\
\hline 1 & 48 & 42 & 125 & $88 / 06 / 20202: 28: 47 \mathrm{pm}$ \\
\hline 2 & 41 & 43 & 116 & $88 / 06 / 20282: 21: 48 \mathrm{pm}$ \\
\hline 3 & 42 & 48 & 218 & $08 / 06 / 20202: 22: 49 \mathrm{pm}$ \\
\hline 4 & 43 & 42 & 125 & $88 / 06 / 20202: 23: 50 \mathrm{pm}$ \\
\hline 5 & 40 & 43 & 125 & 88/06/2020 2: $24: 51 \mathrm{pm}$ \\
\hline 6 & 42 & 47 & 125 & $88 / 06 / 20202: 25: 52 \mathrm{pm}$ \\
\hline 7 & 43 & 48 & 125 & $08 / 06 / 20202: 26: 53 \mathrm{pm}$ \\
\hline 8 & 47 & 42 & 125 & $88 / \oslash 6 / 20222: 27: 54 \mathrm{pm}$ \\
\hline 9 & 48 & 45 & 134 & $88 / 06 / 20204: 28: 55$ pm \\
\hline 18 & 42 & 38 & 156 & $88 / 06 / 20204: 29: 56 \mathrm{pm}$ \\
\hline 11 & 43 & 39 & 125 & $08 / 66 / 20204: 30: 57 \mathrm{pm}$ \\
\hline 12 & 42 & 51 & 167 & $68 / 66 / 20224: 31: 58 \mathrm{pm}$ \\
\hline
\end{tabular}

Figure 12 Database Values

Figure 12 shows the all database values from database. 
International Journal of Engineering Applied Sciences and Technology, 2020

Vol. 5, Issue 6, ISSN No. 2455-2143, Pages 228-235

Published Online October 2020 in IJEAST (http://www.ijeast.com)

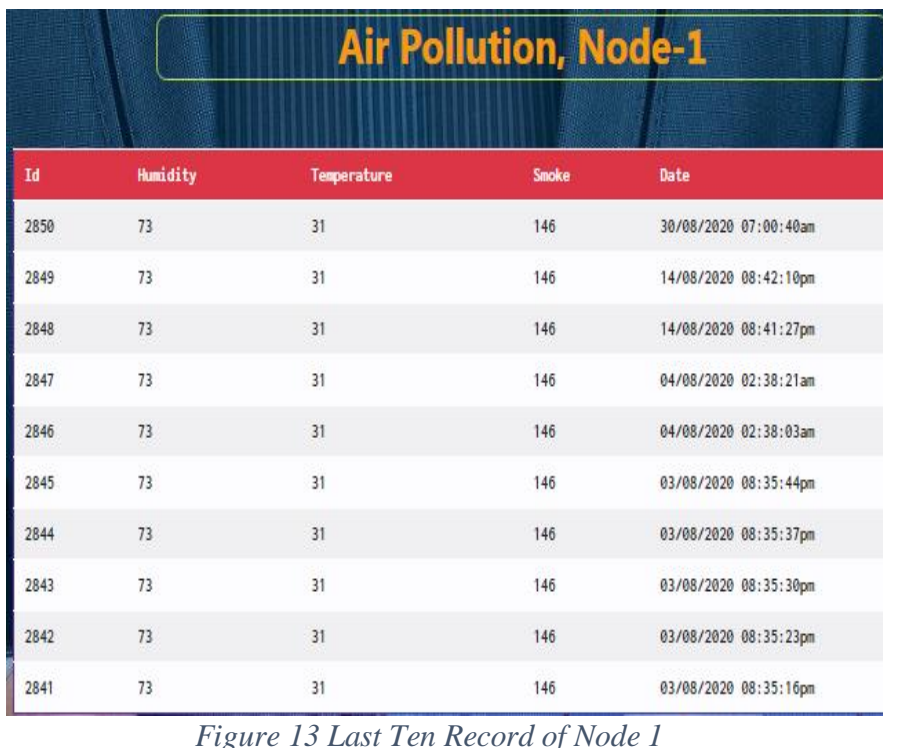

Figure 13 shows the last ten values from database.

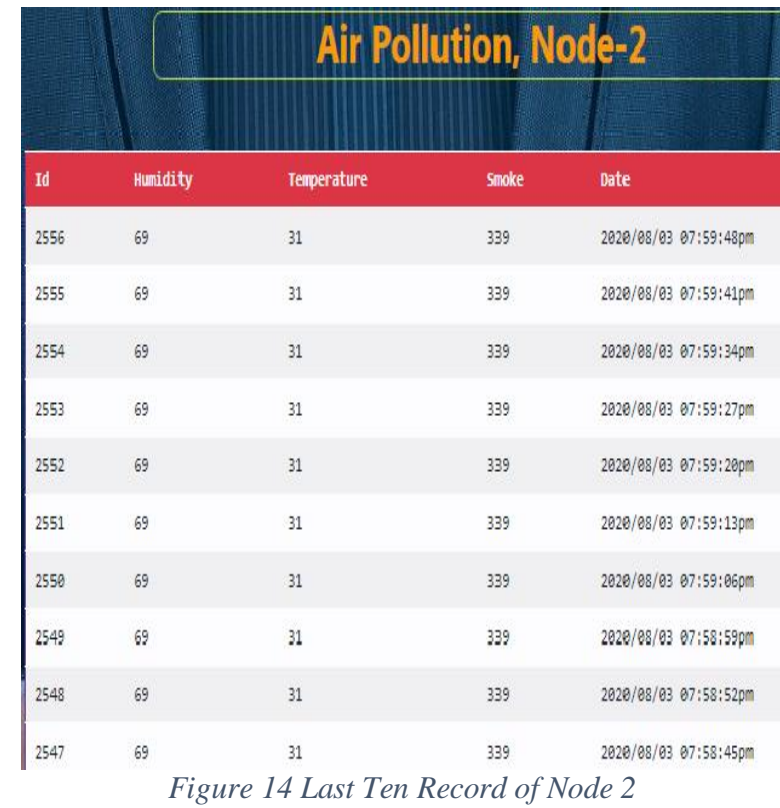

Figure 14 shows the last ten values from database.

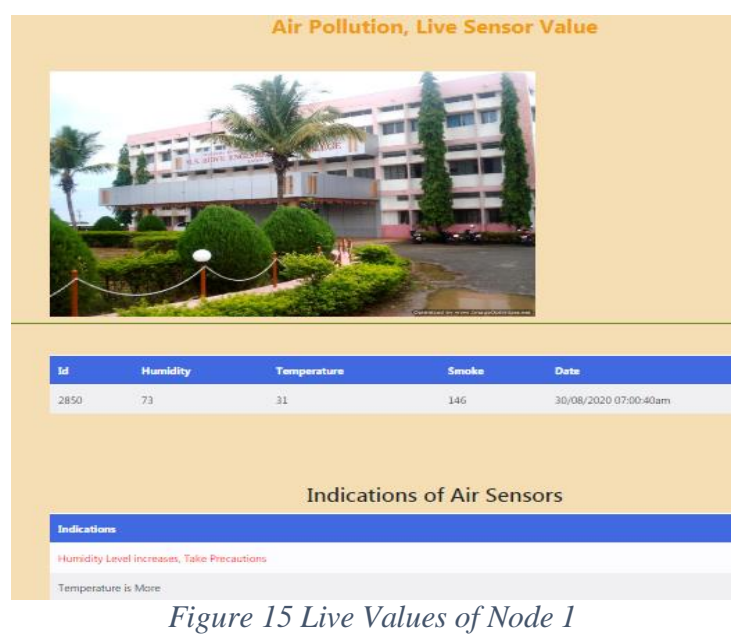

Figure 15 shows the current values of all sensor's values of Node-1

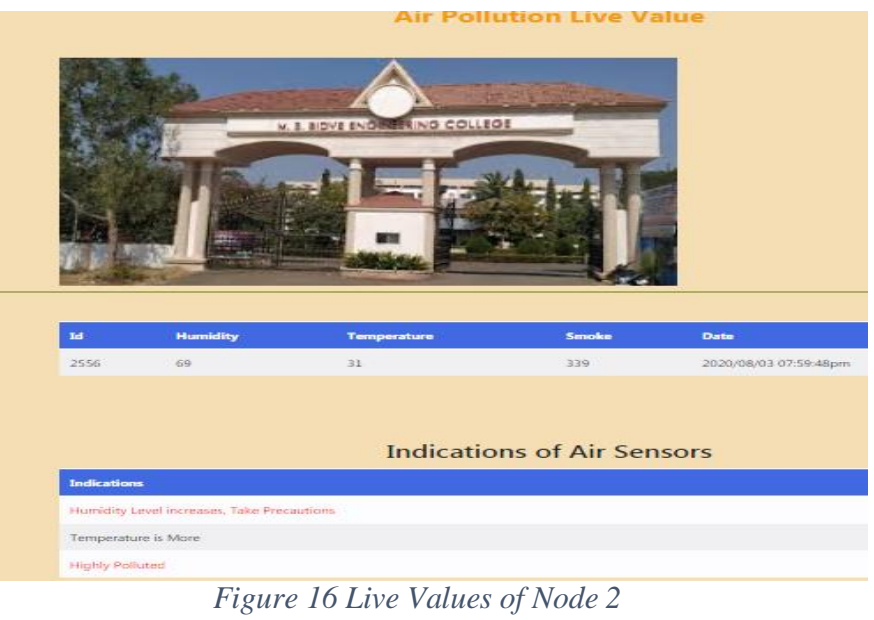

Figure 16 shows the current values of all sensors values of Node-1

\section{$\square$ ThingSpeak" Chanels $\rightarrow$ Apps - Suppotr -

Air Pollution Monitoring System

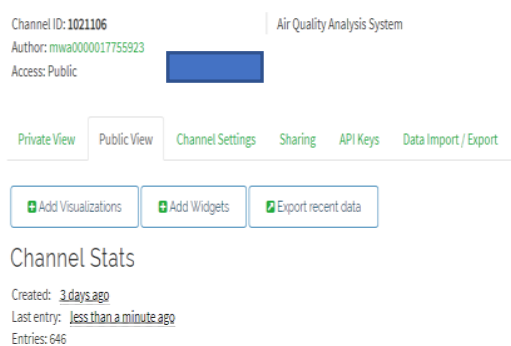

Figure 17 ThingSpeak Cloud Dashboard

Figure 17 ThingSpeak Cloud Dashboard 


\section{International Journal of Engineering Applied Sciences and Technology, 2020 \\ Vol. 5, Issue 6, ISSN No. 2455-2143, Pages 228-235 \\ Published Online October 2020 in IJEAST (http://www.ijeast.com)}

\section{ACKNOWLEDGMENT}

It is my pleasure to get this opportunity to thank my beloved and respected Guide Prof. S.R. Tandle who imparted valuable basic knowledge of data mining specifically related to my project topic. He was also kind enough to spare his valuable time to guide me in making my dissertation. I earnestly express gratitude toward him for a predictable direction, motivation, and thoughtful disposition all through the all-out work, which I am certain, will go far in my life. I owe genuine much appreciated, beyond what I can communicate, towards my head, Computer Engineering Department, Prof. S.R. Tandle M. S. Bidve Engineering College, Latur as all the success is the result of his affectionate encouragement.

\section{CONCLUSION}

In this task utilized Arduino microcontroller IOT Innovation is proposed to improve the idea of air. With the usage of IoT development overhauls the route toward checking various pieces of the condition, for instance, air quality noticing issues proposed right now sensor gives the sentiment of different kinds of hazardous gas and Arduino is the center of this assignment. Which controls the entire method. The WiFi module relates the whole system to the web. For additional upgrade more sensors can be added to take more boundaries to get liberated from air contamination and to shield risky impacts from it.

\section{REFERENCES}

[1] Riteeka Nayak, Malaya RanjanPanigrahy, Vivek Kumar Rai and T Appa Rao. IOT based air pollution monitoring system., Imperial Journal of Interdisciplinary Research, 2017.

[2] Arushi Singh, Divya Pathak, PrachiPandit, ShrutiPatil, Prof. PritiGolar. IoT based Air and Sound Pollution Monitoring System, March 2017.

[3] PalaghatYaswanthSai. AnIoT Based Automated Noise and Air Pollution Monitoring System. International Journal of Advanced Research in Computer and Communication Engineering, March 2017.

[4] L.Ezhilarasi, K.Sripriya, A .Suganya , K.Vinodhini. A System for Monitoring Air and Sound Pollution using Arduino Controller with IOT Technology. International research Journal in Advanced Engineering and Technology, March 2017.

[5] A.M.Leman. Occupational Safety and Health: Workers and Industrial Safety Monitoring for Sustainable Work Environment Development. Health and Safety, April, 2013. 